CBIE-LACLO 2015

Anais dos Workshops do IV Congresso Brasileiro de Informática na Educação (CBIE 2015)

\title{
O processo de apropriação pedagógica e tecnológica do Tablet na formação do professor de Matemática
}

\author{
Maria Elisabette Brisola Brito Prado ${ }^{1}$, Nielce Meneguelo Lobo da Costa ${ }^{2}$ \\ ${ }^{1}$ Programa de Pós-Graduação em Educação Matemática - Universidade Anhanguera de \\ São Paulo (UNIAN) e Núcleo de Informática Aplicada à Educação - Universidade \\ Estadual de Campinas (UNICAMP), Campinas, SP. \\ ${ }^{2}$ Programa de Pós-Graduação em Educação Matemática - Universidade Anhanguera de \\ São Paulo (UNIAN) \\ bette.prado@gmail.com, nielce.lobo@gmail.com
}

\begin{abstract}
The aim of this study was to identify as a group of five teachers of Mathematics appropriates the pedagogical use of the tablet in the school context.This qualitative research was developed in a continuing education course involving the use of tablets and educational software. Data analysis showed that the pedagogical appropriation of mobile digital technology is composed of several phases, which often are required to be experienced and reflected by the teacher while participating in the course. It is crucial to provide the opportunity for teachers to experience individual and collective reflexive actions in the professional group, trials shares through learning by doing so it can build new references to a new pedagogical practice integrating TDM to curriculum content.
\end{abstract}

Resumo. O objetivo desse estudo foi o de identificar como um grupo de cinco professores de Matemática se apropria do uso pedagógico do tablet no contexto do escolar. Esta pesquisa de caráter qualitativo se desenvolveu em um curso de formação continuada envolvendo o uso de tablets e de softwares educacionais. A análise dos dados mostrou que a apropriação pedagógica da tecnologia digital móvel se constitui de várias fases, as quais, muitas vezes, são necessárias ser vivenciadas e refletidas pelo professor durante a sua formação. É fundamental oportunizar o professor a vivenciar ações reflexivas individuais e coletivas no grupo de profissionais, compartilhamentos de experimentações por meio do aprender-fazendo de modo que possa a construir novos referenciais para um novo fazer pedagógico integrando as TDM aos conteúdos curriculares.

\section{Introdução}

Nos dias atuais as pessoas e, principalmente, os estudantes utilizam as tecnologias digitais móveis (TDM) com muita habilidade e procuram estar sempre conectados se 


\section{CBIE-LACLO 2015}

Anais dos Workshops do IV Congresso Brasileiro de Informática na Educação (CBIE 2015)

comunicando e acessando informações de várias regiões do mundo. Essa geração de estudantes é diferente a de alguns anos atrás, é a geração conhecida como nativos digitais. As crianças e os jovens estudam e ouvem música, se comunicam de várias maneiras pela internet, acessam vídeos, imagens e textos buscando informações e fazem as tarefas de lição de casa, tudo ao mesmo tempo. Esse tipo de comportamento está vinculado à forma imediata com a qual a informação chega ao indivíduo e como ela pode ser produzida e disponibilizada, por meio das tecnologias digitais.

Diante dessa realidade, uma das questões instigadora é como a escola lida com esta situação? Os professores estão preparados para ensinar nesse novo paradigma da sociedade na cultura digital?

Quanto ao uso das tecnologias digitais móveis na escola, o governo brasileiro, desde 2007, tem incentivado por meio de projetos, entre os quais, o Projeto UCA (Um Computador por Aluno) cujo objetivo é a criação e socialização de formas diferentes para se utilizar pedagogicamente os recursos da TDM nas escolas públicas. Mais recentemente, o Ministério da Educação investiu na compra de tablets, que inicialmente foram entregues para os professores do Ensino Médio da rede pública de ensino, para serem utilizados como recurso pedagógico, proporcionando mobilidade e conectividade via $W i-f i$ a conteúdos digitais.

Apesar das experiências com o uso das tecnologias digitais móveis no contexto da Educação Básica serem recentes, existem diversas pesquisas originadas principalmente do Projeto UCA que analisaram o efeito do laptop estar nas mãos dos alunos e seu uso educacional em sala de aula. Dentre tais pesquisas, o estudo de Almeida e Prado (2009), destaca que no dia a dia em sala de aula, o uso do computador móvel pode incentivar novas formas de o aluno se relacionar com as informações, de expressar e representar conhecimentos, gerando com isso "[...] mudanças nas relações entre todos os elementos presentes nesse espaço e em seus modos de atuar, que impulsionarão transformações no contexto escolar" (p. 5). Nesse sentido, Silva e Silva (2014), observaram em suas pesquisas que as experiências desenvolvidas no Projeto UCA têm permitido aos educadores a reorientar o foco do olhar para o papel da escola como integrante da cultura digital móvel.

De fato, antes do surgimento da tecnologia digital móvel as escolas dispunham, quando muito, de laboratórios de informática e o uso do computador dependia de agendamentos prévios e da disponibilidade de acesso, uma vez que normalmente havia um único laboratório para atender um grande número de alunos e professores de uma mesma escola. Agora com essa nova realidade, que caracteriza um novo paradigma de uso da tecnologia na educação, permeada pela presença das TDM nas mãos dos alunos, a gestão escolar e a prática do professor se deparam com novos desafios educacionais.

Isto implica na necessidade de ampliar e aprofundar os estudos sobre o uso das TDM nos espaços escolares, considerando os possíveis impactos que podem ocorrer na prática do professor. Em especial, ressaltamos as tecnologias digitais móveis com touchscreen (tela sensível ao toque), pois elas podem trazer novas possibilidades para os processos de ensino e de aprendizagem. A manipulação no tablet é diferente do que com um clique do mouse. Segundo os estudos de Assis (2014) e de Prado e Padilha (2015), esta característica do dispositivo touchscreem pode propiciar um novo modo de interação com a tecnologia em termos de favorecer o aspecto cognitivo no processo de 
aprendizagem. Os estudos de Bairral (2013) destacam o potencial do dispositivo touchscreen para a aprendizagem no contexto da geometria dinâmica, uma vez que

... a manipulação nesse tipo de ambiente deve ser vista como uma ferramenta cognitiva que potencialize nos aprendizes as suas habilidades de exploração, de elaboração de conjecturas e de construção de diferentes meios de justificá-las (p.8).

Além disso, outras características das TDM poderão despertar a curiosidade e a criatividade dos alunos, possibilitando a colaboração entre eles para novas descobertas, agilidade para a busca de informações e para a comunicação, proporcionando novas formas de interação e de aprendizagens. No entanto, a questão que nos instiga centra-se em compreender como os professores se apropriam dos recursos das TMD para serem utilizados no contexto da escola, com foco nos conteúdos curriculares.

\section{Desenvolvimento da Pesquisa}

O objetivo desse estudo foi o de identificar como um grupo de cinco professores de Matemática se apropria do uso pedagógico do tablet no contexto do ensino de função polinomial do $1^{\mathrm{o}}$ grau. Tais professores atuam no Ensino Fundamental II e Médio da rede estadual da cidade de São Paulo e são participantes de um projeto do Programa Observatório da Educação da CAPES. Este Programa se desenvolve por meio da parceria entre as universidades e as escolas públicas de Educação Básica, visando o desenvolvimento de pesquisas e ações de formação que possam favorecer a melhoria da educação.

Esta pesquisa de caráter qualitativo se desenvolveu no contexto de um curso de formação continuada envolvendo o uso de tablets e de softwares educacionais. Para a coleta de dados os instrumentos utilizados foram: questionário, entrevistas semiestruturadas, diário de campo e os protocolos das atividades desenvolvidas pelos professores participantes durante o curso.

O questionário foi elaborado contendo questões relacionadas ao perfil dos professores, bem como, o nível de familiaridade e conhecimento do tablet tanto em relação ao uso pessoal como profissional. As entrevistas foram realizadas durante e após os encontros de formação, com o intuito de ouvir os relatos dos professores sobre as experiências vivenciadas no curso. Além disso, foram feitos registros das observações e das atividades desenvolvidas pelos professores com o uso de softwares educacionais para a exploração de diferentes registros de representação, particularmente, de gráficos de funções polinomiais do $1^{\circ}$ grau.

A análise dos dados quanto ao processo de apropriação da tecnologia pelos participantes se desenvolveu com base teórica nos estudos de Sandholtz, Ringstaff e Dwyer (1997) e de Almeida e Valente (2011). Esses autores acompanhando as experiências de implantação das tecnologias nas escolas identificaram que a apropriação ocorre de forma gradativa, iniciando pela fase da adoção das tecnologias e domínio operacional para outras que se aproximam de sua prática pedagógica sem o uso das tecnologias para finalmente se apropriarem de seus recursos de forma a integrá-los aos conteúdos curriculares. Sob esse enfoque, Prado e Lobo da Costa (2013) salientam que é a partir de um processo reflexivo e de compartilhamento entre os pares, inclusive com a 
mediação dos formadores que os professores têm condições de construírem novos referenciais, permitindo que a apropriação tecnológica ultrapasse o sentido da utilização meramente operacional para a reconstrução de práticas criativas e inovadoras.

Assim, tendo como base tais princípios, as ações formativas, procurou favorecer o diálogo e a interação entre os componentes do grupo de professores e entre esse grupo e o formador durante a exploração dos recursos do tablet e dos softwares Grapher e Geogebra, que ocorreu de forma contextualizada, a partir de conteúdos matemáticos do currículo escolar.

\section{Descrição e Análise}

Primeiramente apresentamos de forma sucinta o perfil desse grupo de professores que leciona a disciplina de Matemática no Ensino Médio. Dentre os cinco professores, dois possuem idade entre 36 a 41 anos e, três professores, entre 41 a 56 anos. Nenhum desses professores faz uso das tecnologias na prática docente, mas quatro deles já fizeram algum curso básico de informática voltada para a educação. Todos declararam conhecer algum tipo de tablet, mas apenas um professor faz uso pessoal no seu dia a dia.

O interesse dos professores por este curso, bem como a participação na pesquisa foi voluntária e o argumento foi pelo fato da escola em que atuam ter recebido os tablets do governo.

As análises preliminares permitiram identificar as reações dos professores ao interagirem com os tablets usando softwares educacionais durante a formação. Nos primeiros contatos com o tablet, os professores manifestaram que consideram importante o uso das TDM para a aprendizagem dos alunos, pois alegaram que os alunos não têm mais interesse pelas aulas convencionais. Em contrapartida, argumentaram que as escolas não estão preparadas fisicamente para o recebimento de dispositivos móveis, existem muitas barreiras que impedem o uso das TDM em sala de aula, tais como: dificuldade de acesso a internet, tempo restrito da aula, falta de apoio e incentivo da gestão escolar e, principalmente a falta de preparo do professor para desenvolver seu conteúdo usando os recursos disponíveis no tablet.

Nesse momento inicial do curso, percebemos que os professores têm a necessidade de expor seus comentários com base muitas vezes num discurso incorporado de que a tecnologia pode contribuir para o aprendizado do aluno, assim como, de explicitar suas preocupações acerca da viabilidade de uso das TDM considerando a realidade escolar. No entanto, entendemos que essa fase, a qual denominamos de periférica, faz parte do processo de apropriação da tecnologia pelo professor. É um momento em que suas reflexões e considerações se relacionam aos aspectos externos, mas que direta ou indiretamente podem influenciar o processo de integração das TDM no contexto escolar. Essa fase periférica que antecede à fase da adoção da tecnologia no sentido abordado por Sandholtz, et al (1997), é muitas vezes necessária de ser vivenciada pelos professores durante a formação.

Passado esse primeiro momento de impacto e na medida em que os professores começaram ter o domínio operacional dos recursos do tablet, ou seja, a vivenciarem a fase da adoção da tecnologia, alguns demonstraram ter consciência da nova realidade 
social e educacional. Houve a manifestação geral do grupo de que o uso das TDM precisa e pode fazer parte do cotidiano profissional do professor, mas que não se trata de algo simples e fácil de acontecer, pois demanda muitas mudanças, principalmente na forma de ensinar. Os depoimentos a seguir ilustram um momento de reflexão dos professores sobre essa nova realidade:

Eu particularmente teria que testar pra ver, mas a partir do momento que você insere uma tecnologia como o tablet na sala de aula, eles [os alunos] largam o celular, eu penso. Chega uma hora que eles acabam acostumando que dentro da sala de aula é um tipo de tecnologia e lá fora é outro tipo de tecnologia que ele vai acessar... (registro do professor-B).

[...] eu acho que a partir do momento em que você leve alguma coisa que fale mais próximo da linguagem deles [dos alunos] eu acho que chamaria mais atenção para se envolver com a aula. Mas não sei como fazer isto com uma classe de quarenta alunos... (registro do professor-E).

Eu posso até usar o tablet na sala de aula, mas depois de explicar na lousa como costumo fazer, senão o aluno pode ficar disperso, fugir do contexto da aula... se o aluno aprendeu direito o que ensinei aí sim posso deixar explorar o tablet (registro do professor-A).

Esse reconhecimento expresso pelos professores na fase de adoção das tecnologias móveis revela uma atitude de abertura e, ao mesmo tempo de preocupações em saber como preparar suas aulas, que envolve ensinar o conteúdo da sua disciplina usando os softwares educacionais e outros recursos disponíveis nos tablets.

Para tanto, as ações formativas foram sendo desenvolvidas abordando atividades próximas do cotidiano dos professores, como por exemplo, atividade de função polinomial com o uso do software Geogebra. Mas, logo no inicio das atividades ficou evidente que a maioria dos professores tinha dificuldades para lidar com o ambiente do Geogebra e, ao mesmo tempo, conseguir manusear de forma confortável os recursos do tablet. Para minimizar esse problema, o formador optou - no inicio das atividades - pelo uso do software Grapher, que também é gratuito e o seu manuseio é bastante simples. Com este software facilmente pode-se criar gráficos de funções, mudar o pano de fundo do plano cartesiano, trocar as cores das grades, ampliar e reduzir imagens por meio do toque e abertura com os dedos. Com isso, torna possível modificar escalas, produzir um efeito de "zoom" e observar particularidades das funções.

A figura 1, a seguir, ilustra uma tela do Grapher representando o gráfico da função $\mathrm{f}(\mathrm{x})=2^{\mathrm{x}}$ e dois momentos de exploração do gráfico com os recursos de touchscreen, evidenciando a possibilidade de com os dedos efetuar "zoom" e observar variações nas escalas. 


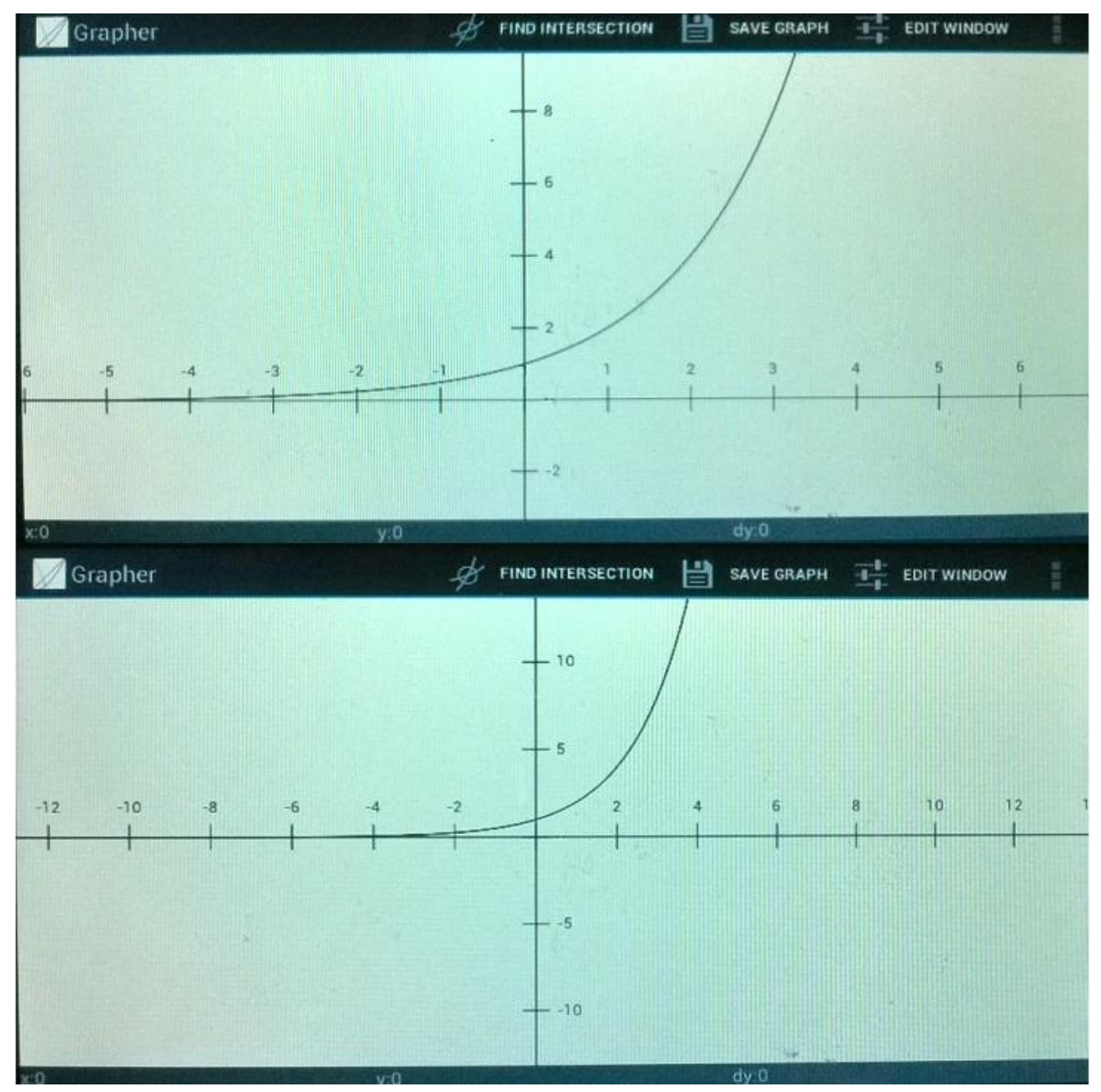

Figura 1. Telas do software Grapher Fonte: Arquivo pessoal

Após um tempo de exploração com o software Grapher realizando as atividades que envolviam funções, os professores puderam constatar a possibilidade que o touchscreen oferece ao movimentar com os dedos e observar o ponto de interseção de gráficos de diversas funções traçadas num mesmo plano cartesiano, no tablet.

Embora, alguns professores demonstraram ter mais dificuldades para interagir com touchscreen pela falta de familiaridade, mas, mesmo assim, todos manifestaram o desejo de aprender a usar as tecnologias digitais móveis e, em particular, os tablets em suas práticas escolares.

Ao utilizarem o tablet para resolverem as atividades sobre funções polinomiais do $1^{\mathrm{o}}$ grau, os professores discutiam com seus pares as possibilidades pedagógicas que conseguiam identificar, como mostram os depoimentos a seguir na situação em que desenvolviam a criação do gráfico $\mathrm{f}(\mathrm{x})=\mathrm{x}-1$ usando os softwares Grapher e o Geogebra. 


\section{CBIE-LACLO 2015}

Anais dos Workshops do IV Congresso Brasileiro de Informática na Educação (CBIE 2015)

No tablet é mais fácil porque posso mostrar para o aluno o coeficiente linear no gráfico e através de zoonm o aluno pode perceber as mudanças de valores e que a reta permanece a mesma independente dos valores de y.(registro do professorE).

É mais fácil e rápido- apenas com um toque - confirmar para o aluno, o mesmo gráfico com valores diferentes. $O$ aluno gosta do visual fica mais fácil perceber e analisar os gráficos e comparar as funções. (registro do professor-B).

Com o uso do software [o Grapher] fica mais fácil para o aluno identificar os pontos... (registro do professor-B)

Podemos observar nos depoimentos dos professores que eles apontam algumas possibilidades, principalmente em termos de facilitar a visualização. Ficou evidente que há uma tendência de o professor adotar a mesma atitude que habitualmente é utilizada em sala de aula, como por exemplo, mostrar no tablet ou no computador um gráfico gerado por um determinado software para aluno.

É comum o professor transferir aquilo que faz no seu cotidiano, ministrando uma aula na lousa para uma aula similar, como por exemplo, usar o PowerPoint para projetar o mesmo conteúdo da lousa. Isso significa "passar a limpo" a mesma aula usando uma tecnologia digital. No entanto, essa atitude pode ser entendida como parte do processo de apropriação da tecnologia.

Outra atitude do grupo de professores que foi observada, mesmo tendo demonstrado interesse em fazer o uso do tablet em suas aulas, diz respeito aos seus argumentos ressaltando ser necessário primeiro ensinar um determinado conteúdo usando a lousa e o giz, para depois explorar o tablet de modo a auxiliar na visualização e análise dos gráficos.

Entretanto, esta forma de utilizar as tecnologias pode ser vista como uma das fases intermediária do processo de apropriação da tecnologia pelo professor. Como já foi dito, o processo de apropriação pedagógica da tecnologia é gradativo. O importante é a formação criar condições para que situações desta natureza sejam refletidas no coletivo do grupo de modo a repensarem e a explorarem novas maneiras de utilizar as potencialidades dos recursos tecnológicos.

Isso significa que a apropriação pedagógica do uso das tecnologias digitais no sentido de integrar seus recursos aos conteúdos curriculares requer do professor um processo de construção e de reconstrução de conhecimentos. Nesse sentido, um dos professores do grupo, que já tinha familiaridade com o tablet e usa softwares no ensino de matemática, expressou seu entendimento sobre o uso pedagógico das TDM:

"[...] com as tecnologias o aluno explora e integra com conceitos matemáticos e isso requer outro tipo de aula... mas, nós não formos formados para isto" (registro do professor-A) 
De fato, o professor precisa ser preparado para reconstruir a sua prática pedagógica integrando as tecnologias digitais, uma vez que o centro do processo educativo nesse contexto não está no professor, nem no aluno, está no processo interativo do aluno com as tecnologias, entre os alunos e entre os alunos e o professor, enquanto aquele que faz a mediação pedagógica.

\section{Algumas Considerações}

As análises preliminares dessa pesquisa que teve como objetivo identificar como um grupo de cinco professores de Matemática se apropria do uso pedagógico do tablet no contexto do ensino de função polinomial do $1^{\circ}$ grau, apontam aspectos relevantes a serem considerados em propostas de formação continuada do professor para utilizar as tecnologias digitais móveis nos processos de ensino e aprendizagem.

Nos processos formativos é preciso criar situações em que o professor aprenda não apenas a operacionalizar os recursos tecnológicos, mas que possa atribuir sentido pessoal e profissional para o seu uso. Este estudo mostrou que processo de apropriação pedagógica da tecnologia se constitui de várias fases, as quais, muitas vezes, são necessárias ser vivenciadas e refletidas pelo professor durante a sua formação. É fundamental oportunizar o professor a vivenciar ações reflexivas individuais e coletivas no grupo de profissionais, compartilhamentos de experimentações por meio do aprenderfazendo de modo que possa a construir novos referenciais para um novo fazer pedagógico integrando as TDM aos conteúdos curriculares.

Esse enfoque da formação é necessário para que na sociedade da cultura digital os professores possam preparar os estudantes, a geração dos nativos digitais, para que não sejam apenas consumidores de informações, mas sim produtores críticos e responsáveis que expressam e compartilham conhecimento na rede tecnológica para uma rede de aprendizagem.

\section{Referências}

Almeida, M. E. B. e Prado, M. E. B. B. (2009). Formação de Educadores para o uso dos computadores portáteis: indicadores de mudança na prática e no currículo. Anais da VI Conferência Internacional de Tecnologias de Informação e Comunicação na Educação. Braga, Portugal.

Almeida, M. E. B. e Valente, J. A. (2011). Tecnologias e Currículo: trajetórias convergentes ou divergentes? São Paulo: Paulus.

Assis, A. R. (2014). Tablets e Aprendizagem de Geometria na Formação Inicial de Professores. In: XVIII EBRAPEM - Recife: Universidade Federal de Pernambuco. Disponível em: <http://www.lematec.noip.org/CDS/XVIIIEBRAPEM/PDFs/GD6/assis6.pdf>. Acesso em: Jun de 2015.

Bairral, M. A. (2013). Do clique ao touchscreen: Novas formas de interação e de aprendizado matemático. In 36 a Reunião Nacional da Anped. Sistema Nacional de Educação e Participação Popular: Desafios para as Políticas Educacionais. Goiânia: 
Anped/UFG. Disponível em: <http://36reuniao.anped.org.br/trabalhos/177-trabalhosgt19-educacao-matematica>. Acesso em: Mar de 2015.

Padilha, W. R. e Prado, M. E. B. B. (2015). O professor de Matemática e as Tecnologias Digitais Móveis no ensino de Função. Acta Latinoamérica de Matemática Educativa - Relme-29. Panamá, Panamá.

Prado, M. E. B. B. e Lobo da Costa, N. M. (2013). O processo de apropriação das TIC e a reconstrução de novas práticas no ensino de matemática. In: Actas VII Congreso Iberoamericano de Educación Matemática - CIBEM. Montevidéu, Uruguai. p. 69736980. Disponível em: <http://www.cibem7.semur.edu.uy/7/actas/pdfs/588.pdf>. Acesso em: Jun de 2015.

Sandholtz, J. H., Ringstaff, C. e Dwyer, D.C. (1997). Ensinando com Tecnologia: criando salas de aula centradas no aluno. Porto Alegre: Ed. Artes Médicas.

Silva, J. M. e Silva, M. da G. M. (2014). A Escola e o Currículo em Tempos de Mobilidade e Conexão: o uso dos computadores portáteis na educação. In: Anais do Anais dos Workshops do Congresso Brasileiro de Informática na Educação WCBIE. Dourados, MS. p. 282-291. Disponível em: <http://www.brie.org/pub/index.php/wcbie/article/view/3227/2788>. Acesso em: Abr de 2015. 